\title{
Genetic Predisposition to Thrombophilia in Inflammatory Bowel Disease
}

\author{
Maria Cappello, MD,* Stefania Grimaudo, PhD, $\dagger$ Ivana Bravatá, MD,* Claudia Randazzo, MD,* \\ Rosaria Maria Pipitone, PhD, † Anna Licata, MD, + Calogero Cammá, MD, $\S$ and Antonio Craxí, MD $\S$
}

Background: Inflammatory bowel disease (IBD) is linked to a definite risk of thromboembolic events (TE), but data on the role of prothrombotic genetic mutations are conflicting.

Study: Fourteen genetic factors involved in TE pathogenesis were investigated in a homogeneous cohort of Sicilian patients with IBD with and without history of TE and in healthy controls. Forty IBD patients (21 CD, 19 UC) and 20 healthy individuals were enrolled. Genetic testing was based on the reverse hybridization principle by a commercial assay that analyzes 14 polymorphisms involved in thrombophilia and cholesterol metabolism. The rate of genetic polymorphisms and mutations was compared between IBD patients and healthy controls.

Results: No significant difference in allelic frequency was found between IBD patients and controls except AGT T/T, though a trend toward significance was found also for ACE D/D. Eight out of 9 patients with earlier history of TE had more than 1 polymorphism, compared with 12 out of 31 without TE. In patients with IBD the mutation AGT T/T was related to male sex $(P<0.0259)$ and, marginally, to arterial hypertension $(P<0.06)$ and diabetes $(P<0.09)$.

Conclusions: Our data confirm a definite risk of TE in IBD $(22.5 \%$ of our series). An increased frequency of the genotypes ACE D/D and AGT T/T, never reported so far, was found. In IBD patients TE has a multifactorial genesis with involvement of several genes as well and acquired factors. Genetic screening for prothrombotic factors could help segregate IBD patients at higher risk of TE.

Key Words: thrombophilia, inflammatory bowel disease, genetic mutations

(J Clin Gastroenterol 2011;45:e25-e29)

U cerative Colitis (UC) and Crohn's disease (CD) are idiopathic inflammatory conditions of the bowel that can involve organs other than the gastrointestinal tract. The reported frequency of extraintestinal manifestations ranges from $6 \%$ in a single population-based study ${ }^{1}$ to $47 \%$ in case control studies., ${ }^{2,3}$ Vascular complications, mostly throm-

Received for publication January 8, 2010; accepted June 3, 2010.

From the *Sezione e U.O.C. di Gastroenterologia; $\dagger$ Laboratorio di Patologia Molecolare; $₫$ Internal Medicine, Sezione di Gastroenterologia; and §Gastroenterology, Sezione di Gastroenterologia, Di.Bi.M.I.S., Universitá di Palermo, Palermo, Italy.

Source of support: none.

Conflict of interest disclosure: none declared.

These results have never been published previously except in the form of an abstract to the 2008 UEGW Congress in Vienna, and is not under consideration (in whole or in part) for publication elsewhere.

Reprints: Maria Cappello, MD, Sezione e U.O.C. di Gastroenterologia, Dipartimento Biomedico di Medicina Interna e Specialistica, Piazza Delle Cliniche 2, 90127, Palermo, Italy (e-mail cmarica@tin.it).

Copyright (C) 2011 by Lippincott Williams \& Wilkins boembolic events (TE), have been described, ${ }^{1,4,5}$ and IBD patients have a 3 -fold risk of deep vein thrombosis and pulmonary embolism as compared with the general population. ., $^{2}$ The reported frequency of TE in IBD varies widely in the literature ${ }^{4,5}$ from $0.3 \%$ in clinical studies to $41 \%$ in autoptic studies. The annual incidence rate of venous thromboembolism in both UC and CD was approximately $0.5 \%$ in a population-based cohort of IBD patients from Manitoba. ${ }^{6}$ Arterial TE have also been reported $^{7,8}$ and, more recently, $\mathrm{CD}$ has been associated to a higher rate of cerebral arterial TE whereas an increased risk of cardiac arterial TE was evidentiated in all IBD patients. ${ }^{9}$ TE are more frequent in young IBD patients and carry a significant risk of mortality. ${ }^{10}$ Many IBD patients with TE have active disease or a recent history of major abdominal surgery. By converse, a large study found that $77 \%$ of peripheral venous thromboses occurred whereas the disease was in clinical remission. ${ }^{4}$ It has hence been suggested that IBD may be associated with a thrombotic tendency independent from disease activity. Corticosteroids, often used chronically in these patients because of steroid dependency, can also induce a hypercoagulable state and subsequently increase the thrombotic risk. ${ }^{11}$ Finally, several autoptic studies had showed in CD patients microthrombi located in blood vessels of the intestinal mucosa, ${ }^{12}$ suggesting that vascular involvement could be the first pathogenetic step in the development of mucosal damage.

Risk factors for thrombosis are classified as acquired and genetic. Acquired risk factors, all frequent in IBD patients, include inflammation, prolonged immobilization or hospitalization, surgery, steroid therapy, fluid depletion, smoking, oral contraceptives, central venous catheters, and hyperhomocysteinemia. The most common genetic prothrombotic factors are Factor V Leiden (FVL), prothrombin G20210A mutations, and homozygous C677T mutation in the methylenetetrahydrofolate reductase (MTHFR). ${ }^{13}$ Over the last years, discrepant results were reported on their role in TE in IBD patients. ${ }^{10,14-30}$ Most studies found no significant difference in the rate of the above mentioned mutations between IBD patients who developed TE and subjects without IBD who experienced TE, but at least 2 reports suggest an increased frequency of mutated alleles for thrombophilia in IBD. ${ }^{21,31}$ Two more recent studies $^{32,33}$ identified an increased expression of other candidate genes for TE, offering new clues for further research.

The aim of our study has been to investigate an extended panel of genetic factors associated with prothrombotic condition in a homogeneous cohort of Mediterranean IBD patients with and without TE compared with a healthy control population. 


\section{MATERIALS AND METHODS}

Forty consecutive IBD patients followed up at the Gastroenterology and Hepatology Unit of the University Hospital of Palermo were enrolled between December 2007 and May 2008. UC and CD were diagnosed on classical clinical, endoscopic, histological, and radiological criteria. Twenty healthy individuals with personal and family history negative for TE were used as healthy controls. Information regarding age, sex, type of IBD, disease localization, extraintestinal manifestations, disease duration and activity, therapy, earlier TE, familial predisposition for IBD and/or TE and risk factors for TE and/or cardiovascular disease (smoking, hypertension, diabetes mellitus, dyslipidemia, oral contraceptives, and hormonereplacement therapy) were registered in a dedicated database.

Fasting peripheral venous blood samples were collected in vacutainer tubes that contained EDTA for mutation analysis and for other blood tests $(\mathrm{Hb}, \mathrm{WBC}$, PLT, ESR, CRP, total cholesterol, HDL-cholesterol, fibrinogen). They were stored at $-20^{\circ} \mathrm{C}$ until determination. The following 14 gene polymorphisms were evaluated using Cardio and Thrombo Test (Nuclear Laser Medicine srl, Settala, Milano, Italy): 2 polymorphisms of Factor V (Factor V R506Q and Factor V H1299R), 1 polymorphism of Factor II (prothrombin G20210A), 2 polymorphisms of methylenetetrahydrofolate reductase (MTHFR C677 T and MTHFR A1298C), 1 polymorphism of cystathionine $\beta$ synthase (CBS T833C/844ins68), 1 polymorphism of plasminogen activator inhibitor (PAI-1 4G/4G), 1 polymorphism of cholesterol ester transfer protein (CEPT I405 V), 1 polymorphism of platelet glycoprotein IIIa (GPIIIa T1565C), 1 polymorphism of cholesterol 7ahydroxylase (CYP7A1 A278C), 1 polymorphism of angiotensin-converting enzyme (ACE D/D), 2 polymorphisms of genes encoding for apolipoproteins (ApoE T112C and T158C), and 1 polymorphism for angiotensinogen (AGT M235 T).

The test is based on the reverse hybridization principle and includes 3 steps: (1) DNA is extracted from anticoagulated blood by a rapid procedure using 6100 PREP STATION (Applied Biosystems, Monza, Milano, Italy), a nucleic acids automatic purification system; (2) relevant gene sequences are simultaneously amplified by "real time" PCR and biotin-labelled; (3) amplification products are hybridized to a test strip which contains allele-specific (wild-type and mutant) oligonucleotide probes as an array of parallel lines. Bound biotinylated sequences are detected using streptavidin-alkaline phosphatase and color substrates.

Statistical analysis has been carried out using the software Statistical Analysis System (SAS, Cary, NC). Continuous variables are expressed as mean \pm standard deviation, categorical variables as rate or percentage. Chisquare test and Fisher exact test when necessary have been used to compare genotypic distribution and allelic frequency. A difference was considered statistically significant when $P<0.05$.

\section{RESULTS}

Twenty-six women and 14 men were investigated; mean age was $47.1(\mathrm{SD} \pm 17.24)$ years. Twenty-one had $C D$ and nineteen had UC. Patients' baseline features are given in Table 1 . Nine IBD patients $(22.5 \%)$ had a history of TE
TABLE 1. Demographic and Clinical Features of Patients With Inflammatory Bowel Disease

\begin{tabular}{|c|c|}
\hline & IBD $(n=40)$ \\
\hline Men/women & $14 / 26$ \\
\hline Age (years, mean $\pm \mathrm{SD})$ & $47.1 \pm 17.24$ \\
\hline $\mathrm{CD} / \mathrm{UC}$ & $21 / 9$ \\
\hline Duration of disease, (years, mean \pm SD) & $5.17 \pm 7.2$ \\
\hline \multicolumn{2}{|l|}{ Location/extension, $\mathrm{n}(\%)$} \\
\hline Ileum & $5(23.8)$ \\
\hline Ileum + colon & $13(61.9)$ \\
\hline Colon & $3(14.3)$ \\
\hline Proctitis & $2(10.5)$ \\
\hline Procto-sigmoiditis & $4(21)$ \\
\hline Left-sides colitis & $3(15.8)$ \\
\hline Pancolitis & $10(52.6)$ \\
\hline \multicolumn{2}{|l|}{ Arthropathy, n (\%) } \\
\hline Axial & $2(5)$ \\
\hline Peripheral & $8(20)$ \\
\hline \multicolumn{2}{|l|}{ Treatment, n (\%) } \\
\hline Only 5-ASA & $12(30)$ \\
\hline Steroids & $15(37.5)$ \\
\hline Immunosuppressors & $7(17.5)$ \\
\hline Steroids + immunosuppressors & $2(5)$ \\
\hline Biologic & $4(10)$ \\
\hline Previous thrombosis, $\mathrm{n}(\%)$ & $12(30)$ \\
\hline Smokers/ex, n (\%) & $14(35) / 5(12.5)$ \\
\hline Arterial hypertension, $\mathrm{n}(\%)$ & $12(30)$ \\
\hline Dyslipidemia, n $(\%)$ & $5(12.5)$ \\
\hline Diabetes mellitus, n (\%) & $4(10)$ \\
\hline Oral contraceptives, n (\%) & $2(5)$ \\
\hline Hormone-replacement therapy, n (\%) & $4(10)$ \\
\hline Family history of IBD, $\mathrm{n}(\%)$ & $5(12.5)$ \\
\hline Family history of thrombosis, $\mathrm{n}(\%)$ & $8(20)$ \\
\hline Hemoglobin $(\mathrm{g} / \mathrm{dL})($ mean $\pm \mathrm{SD})$ & $12.6 \pm 1.7$ \\
\hline $\operatorname{PLT}\left(\times 10^{3} / \mathrm{L}\right)($ mean $\pm \mathrm{SD})$ & $275 \pm 89.9$ \\
\hline $\operatorname{ESR}(\mathrm{mm} / \mathrm{h})($ mean $\pm \mathrm{SD})$ & $19 \pm 19.7$ \\
\hline $\mathrm{CRP}(\mathrm{mg} / \mathrm{dL})($ mean $\pm \mathrm{SD})$ & $2.1 \pm 2.9$ \\
\hline Total cholesterol $(\mathrm{mg} / \mathrm{dL})($ mean $\pm \mathrm{SD})$ & $172 \pm 62.4$ \\
\hline HDL-cholesterol $(\mathrm{mg} / \mathrm{dL})($ mean $\pm \mathrm{SD})$ & $48 \pm 18.5$ \\
\hline Fibrinogen $(\mathrm{mg} / \mathrm{dL})($ mean $\pm \mathrm{SD})$ & $360 \pm 97.6$ \\
\hline
\end{tabular}

$\mathrm{CD}$ indicates Crohn disease; $\mathrm{CRP}, \mathrm{C}$ reactive protein; ESR, erythrocyte sedimentation rate; IBD, inflammatory bowel disease; UC, ulcerative colitis.

(Table 2). These patients had a mean age of $57.5(\mathrm{SD} \pm 14)$ years. Rates of genetic polymorphisms and mutations are reported in Table 3. No significant difference in allelic frequency was found between IBD patients and controls except AGT $\mathrm{T} / \mathrm{T}$, though a trend toward significance was found also for ACE D/D. No significant difference was observed between $\mathrm{CD}$ and UC patients. Eight out of 9 patients with earlier history of TE had more than 1 polymorphism (Table 4), while in patients without TE this is less frequent $(12 / 31)$ and no more than 2 polymorphisms were observed. Smoking habits and contraceptive consumption in IBD patients were not associated with TE.

For the analysis of mutations of the ACE gene, genotypes $\mathrm{I} / \mathrm{D}$ and $\mathrm{I} / \mathrm{I}$ were pooled and compared with genotype $\mathrm{D} / \mathrm{D}$, whereas for the AGT gene genotypes $\mathrm{M} / \mathrm{M}$ and $\mathrm{M} / \mathrm{T}$ were pooled and compared with genotype $\mathrm{T} / \mathrm{T}$. In patients with IBD the mutation AGT T/T was related with male sex $(P<0.0259)$ and, marginally, with arterial hypertension $(P<0.06)$ and diabetes $(P<0.09)$. 


\begin{tabular}{ll}
\hline TABLE & 2. \\
\hline Patients & \multicolumn{1}{c}{ Type of Vascular Complications in IBD Patients } \\
\hline 1 & Carotid stenosis/Internal jugular vein thrombosis \\
2 & Iliac arterial thrombosis \\
3 & Deep vein thrombosis of the leg \\
4 & Deep vein thrombosis of the leg/Iliac arterial thrombosis \\
5 & Ischemic heart disease/Iliac arterial thrombosis \\
6 & Common iliac vein thrombosis \\
7 & Deep vein thrombosis of the leg \\
8 & Deep vein thrombosis of the leg \\
9 & Transient ischemic attack \\
\hline
\end{tabular}

IBD indicates inflammatory bowel disease.

\section{DISCUSSION}

Research on the role of genetic prothrombotic factors in IBD has led to conflicting results. ${ }^{10,14-30}$ Most studies found no significant difference in the rate of mutations between IBD patients who developed TE and patients without IBD who experienced TE, but at least 2 reports suggest an increased frequency of mutated alleles for thrombophilia in IBD. ${ }^{21,31}$ In the study by Liebman et al, ${ }^{21}$ FVL mutation was found in $36 \%$ of 11 IBD patients with history of TE versus $4 \%$ of 51 IBD patients without history of TE. Similar results were reached by Oldenburg et al. ${ }^{31}$

In the last 2 years, two more studies have addressed this topic looking for expression of a larger panel of polymorphisms. In particular, Koutroubakis et $\mathrm{al}^{32}$ identified an increased expression of the alleles FV R506Q and PAI-1 4G/4G in IBD while Yilmaz et $\mathrm{al}^{33}$ reported an increased allelic frequency of $\beta$-Fibrinogen 455 G-A, MTHFR A1298C and ACE I/D. These results suggest the involvement of factors others than those commonly associated with TE in subjects without IBD. The reason for conflicting results could be due to the different characteristics of patients enrolled in previous studies in terms of genetic background, ethnic origin, sample size, and number of TE. Discrepant results could be explained also by the different mixing in various series of genetic and acquired conditions predisposing to TE. Studies in the Mediterranean area investigating the expression of the most common genes associated with TE, that is FVL, MTHFR mutations, and Factor II G20210A, did not find associations with IBD. ${ }^{20,25,26,30}$ However, as suggested by other studies, in IBD other candidate genes could act as triggers for TE. T2,33 $^{32,31}$

Although the number of patients is small and the number of TE events modest, our study accounts for a consecutive, ethnically homogenous series of Sicilian patients investigated using an extensive panel of 14 genes associated with vascular events which, to our knowledge, has never been assessed in this setting. In agreement with a majority of studies, we were unable to show a different frequency of the most common genetic prothrombotic factors (again FVL, MTHFR mutations and Factor II G20210A) in patients with IBD with or without TE as compared to controls. Nonetheless, we have demonstrated the expression of multiple polymorphisms and mutations in IBD patients with TE, a potentially relevant finding that suggests that multiple genes may contribute to the development and increased risk of TE. We also found an increased frequency of AGT $\mathrm{T} / \mathrm{T}$, which has never been
TABLE 3. Genotypic Polymorphisms in IBD Patients Compared With Healthy Controls

\begin{tabular}{|c|c|c|c|}
\hline Polymorphisms & $\begin{array}{c}\text { IBD } \\
\text { N }(\%)\end{array}$ & $\begin{array}{c}\text { Healthy Controls } \\
\text { N (\%) }\end{array}$ & $\boldsymbol{P}$ \\
\hline \multicolumn{4}{|c|}{ Factor V R506Q (Leiden) } \\
\hline $506 \mathrm{RR}$ & $38(95)$ & $19(95)$ & \\
\hline $506 \mathrm{RQ}$ & $2(5)$ & $1(5)$ & 0.455 \\
\hline $506 \mathrm{QQ}$ & 0 & 0 & \\
\hline \multicolumn{4}{|l|}{ Factor V H1299R } \\
\hline $1299 \mathrm{HH}$ & $32(80)$ & $16(80)$ & \\
\hline $1299 \mathrm{HR}$ & $8(20)$ & $4(20)$ & 0.266 \\
\hline $1299 \mathrm{RR}$ & 0 & 0 & \\
\hline \multicolumn{4}{|c|}{ Prothrombin G20210A } \\
\hline $20210 \mathrm{GG}$ & $40(100)$ & $19(95)$ & \\
\hline 20210 AG & 0 & $1(5)$ & 0.333 \\
\hline 20210 AA & 0 & 0 & \\
\hline \multicolumn{4}{|l|}{ MTHFR C677T } \\
\hline $677 \mathrm{CC}$ & $13(32.5)$ & $5(25)$ & \\
\hline $677 \mathrm{CT}$ & $20(50)$ & $7(35)$ & 0.163 \\
\hline $677 \mathrm{TT}$ & $7(17.5)$ & $8(40)$ & \\
\hline \multicolumn{4}{|l|}{ MTHFR A1298C } \\
\hline $1298 \mathrm{AA}$ & $19(47.5)$ & $10(50)$ & \\
\hline $1298 \mathrm{AC}$ & $15(37.5)$ & $9(45)$ & 0.509 \\
\hline $1298 \mathrm{CC}$ & $6(15)$ & $1(5)$ & \\
\hline \multicolumn{4}{|c|}{ CBS T833C/844ins68 } \\
\hline CTR & $36(90)$ & $16(80)$ & 0.173 \\
\hline CTR/INS & $4(10)$ & $4(20)$ & \\
\hline INS & 0 & 0 & \\
\hline \multicolumn{4}{|l|}{ PAI-1 } \\
\hline $4 \mathrm{G} / 4 \mathrm{G}$ & $5(12.5)$ & $7(35)$ & \\
\hline $4 \mathrm{G} / 5 \mathrm{G}$ & $23(57.5)$ & $8(40)$ & 0.117 \\
\hline $5 \mathrm{G} / 5 \mathrm{G}$ & $12(30)$ & $5(25)$ & \\
\hline \multicolumn{4}{|l|}{ CEPT I $405 \mathrm{~V}$} \\
\hline $\mathrm{I} / \mathrm{I}$ & $17(42.5)$ & $7(55)$ & \\
\hline $\mathrm{I} / \mathrm{V}$ & $21(52.5)$ & $12(60)$ & 0.85 \\
\hline $\mathrm{V} / \mathrm{V}$ & $2(5)$ & $1(5)$ & \\
\hline \multicolumn{4}{|l|}{ GPIIIa T1565C } \\
\hline $\mathrm{T} / \mathrm{T}$ & $31(77.5)$ & $14(70)$ & \\
\hline $\mathrm{T} / \mathrm{C}$ & $8(20)$ & $6(30)$ & 0.556 \\
\hline $\mathrm{C} / \mathrm{C}$ & $1(2.5)$ & 0 & \\
\hline \multicolumn{4}{|l|}{ CYP7A1 A278C } \\
\hline $\mathrm{A} / \mathrm{A}$ & $12(30)$ & $4(20)$ & \\
\hline $\mathrm{A} / \mathrm{C}$ & $19(47.5)$ & $12(60)$ & 0.624 \\
\hline $\mathrm{C} / \mathrm{C}$ & $9(22.5)$ & $4(20)$ & \\
\hline \multicolumn{4}{|l|}{$\mathrm{ACE}$} \\
\hline $\mathrm{D} / \mathrm{D}$ & $20(50)$ & $11(57.89)$ & \\
\hline $\mathrm{I} / \mathrm{D}$ & $17(42.5)$ & $7(36.84)$ & 0.075 \\
\hline $\mathrm{I} / \mathrm{I}$ & $3(7.5)$ & $1(5.26)$ & \\
\hline \multicolumn{4}{|l|}{ APO E E2/E3/E4 } \\
\hline E2/E2 & 0 & $1(5)$ & \\
\hline $\mathrm{E} 2 / \mathrm{E} 3$ & $4(10)$ & 0 & \\
\hline $\mathrm{E} 2 / \mathrm{E} 4$ & $1(2.5)$ & 0 & 0.375 \\
\hline E3/E3 & $29(72.5)$ & $17(85)$ & \\
\hline $\mathrm{E} 3 / \mathrm{E} 4$ & $5(12.5)$ & $2(10)$ & \\
\hline E4/E4 & $1(2.5)$ & 0 & \\
\hline \multicolumn{4}{|l|}{ AGT M235T } \\
\hline $\mathrm{M} / \mathrm{M}$ & $17(42.5)$ & $5(25)$ & \\
\hline $\mathrm{M} / \mathrm{T}$ & $11(27.5)$ & $11(55)$ & 0.011 \\
\hline $\mathrm{T} / \mathrm{T}$ & $12(30)$ & $4(20)$ & \\
\hline
\end{tabular}

ACE indicates angiotensin-converting enzyme; AGT, angiotensinogen; APO, apolipoproteins; CBS, cystathionine beta synthase; CEPT, cholestero ester transfer protein; CYP7A1, cholesterol 7a-hydroxylase; GPIIIa, platelet glycoprotein IIIa; IBD, inflammatory bowel disease; MTHFR, methylenetetrahydrofolate reductase; PAI-1, plasminogen activator inhibitor-1.

reported so far in IBD, and, even if not statistically significant, of the genotypes ACE D/D, confirming the results of Yilmaz et al. These genes are more commonly 
TABLE 4. Genetic Profile in IBD Patients With TE

Patient-1 MTHFR C677 T heterozygous, MTHFR A1298C heterozygous, PAI-1 4G/4G homozygous, AGT M235 T homozygous Patient-2 MTHFR C677 T homozygous, CYP7A1 A278C homozygous

Patient-3 MTHFR A1298C homozygous, CYP7A1 A278C homozygous, ACE D/D homozygous, AGT M235 T homozygous

Patient-4 MTHFR A1298C homozygous, ACE D/D homozygous

Patient-5 MTHFR C677 T homozygous, ACE D/D homozygous

Patient-6 FV H1299R heterozygous, MTHFR C677 T heterozygous, MTHFR A1298C heterozygous, ACE D/D homozygous, AGT M235 T homozygous

Patient-7 MTHFR C677 T heterozygous, A1298C heterozygous, GPIIIa T1565C homozygous

Patient-8 FV R506Q heterozygous, MTHFR C677 T heterozygous, MTHFR A1298C heterozygous, ACE D/D homozygous, PAI-1 $4 \mathrm{G} / 4 \mathrm{G}$ homozygous

associated with arterial TE. ACE plays a role in platelet activation and aggregation, while the AGT gene is linked to early atherosclerosis, essential hypertension and atrial fibrillation. ${ }^{34,35}$ Indeed, early atherosclerosis is a clinical feature common to several inflammatory and immunological diseases and a well-recognized marker of accelerated atherogenesis, that is the intima-media thickness (IMT) of the common carotid artery, has recently been detected in patients with inflammatory bowel disease. ${ }^{36}$ Genetic polymorphisms of AGT and ACE predisposing to atherogenesis could be crucial in determining mesenteric microvascular thrombosis that many investigators believe to be a contributing factor in the pathogenesis of IBD. In CD a pathological angiogenesis could also play a critical role in perpetuating and amplifying the inflammatory process. These findings are in keeping with a recent epidemiology study $^{37}$ that found an increased rate of arterial vascular complications in IBD.

Genetic profiling and identification of acquired factors could both help in stratifying patients at risk to choose the best candidates for heparin prophylaxis thus minimizing side effects. Even if results of clinical trials, in which anticoagulant drugs were used as the first treatment for IBD, have shown that they are safe, ${ }^{38}$ fear of hemorrhagic complications is still a matter of concern among gastroenterologists worldwide. At the present time heparin is recommended in hospitalized patients with IBD in general by the American Society of Thromboembolism, ${ }^{39}$ while the British Society of Gastroenterology ${ }^{40}$ recommends pharmacological prophylaxis for TE only in hospitalized patients with severe UC.

We suggest the use of genetic profiling for TE to improve the selection of patients at risk in view also of the potential clinical implications of the recent large retrospective study by Grainge et $\mathrm{al}^{41}$ which reports an even higher risk of TE during flares of IBD in nonhospitalized patients, thus extending the indications to heparin prophylaxis.

In conclusion, our study focused on a comprehensive evaluation of genetic factors related to thrombophilia in a group of IBD patients with or without history of TE, and found a possible role of two genes, ACE and AGT, which needs, in consideration of the small sample size, to be confirmed in larger series and in multicentric studies.

\section{REFERENCES}

1. Bernstein $\mathrm{CN}$, Blanchard JF, Rawsthorne $\mathrm{P}$, et al. The prevalence of extraintestinal diseases in inflammatory bowel disease: a population-based study. Am J Gastroenterol. 2001; 96:1116-1122.
2. Ricart E, Panaccione R, Loftus EV, et al. Autoimmune disorders and extraintestinal manifestations in first-degree familial and sporadic inflammatory bowel disease. A casecontrol study. Inflamm Bowel Dis. 2004;3:207-214.

3. Greenstein AJ, Janowitz HD, Sachar DB. The extra-intestinal complications of Crohn's disease and ulcerative colitis: a study of 700 patients. Medicine (Baltimore). 1976;55: 401-412.

4. Talbot RW, Heppel J, Dozois RR, et al. Vascular complications in IBD. Mayo Clin Proc. 1986;61:140-145.

5. Solem CA, Loftus EV, Tremaine WJ, et al. Venous thromboembolism in inflammatory bowel disease. Am J Gastroenterol. 2004;99:97-101.

6. Bernstein CN, Blanchard JF, Houston DS, et al. The incidence of deep venous thrombosis and pulmonary embolism among patients with IBD: a population-based cohort study. Thromb Haemost. 2001;85:430-434.

7. Zünd G, Enzler MA, Brunner U, et al. Acute ischemia of the lower extremity in an adolescent with Crohn disease. Vasa. 1992;21:216-218.

8. Lengle SJ, Nadler P, Jordan GW. Arterial thrombosis in ulcerative colitis. Transcatheter thrombolytic therapy. West J Med. 1995;162:543-547.

9. Bernstein CN, Wajda A, Blanchard JF. The incidence of arterial thromboembolic disease in inflammatory bowel disease: a population-based study. Clin Gastroenterol Hepatol. 2008;6:41-45.

10. Grip O, Svensson PJ, Lindgren S. Inflammatory bowel disease promotes venous thrombosis earlier in life. Scand $J$ Gastroenterol. 2000;35:619-623.

11. Koutroubakis IE. Unravelling the Mechanism of Thrombosis in Inflammatory Bowel Disease. Am J Gastroenterol. 2001; 96:1325-1327.

12. Wakefield AJ, Sawyerr AM, Dhillon AP, et al. Pathogenesis of Crohn's disease: multifocal gastrointestinal infarction. Lancet. 1989;2:1057-1062.

13. Seligsohn U, Lubetsky A. Genetic susceptibility to venous thrombosis. N Engl J Med. 2001;344:1222-1231.

14. Guedon C, Le Cam-Duchez V, Lalaude O, et al. Prothrombotic inherited abnormalities other than FVL mutation do not play a role in venous thrombosis in inflammatory bowel disease. Am J Gastroenterol. 2001;96:1448-1454.

15. Danese S, Papa A, Saibeni S, et al. Inflammation and coagulation in inflammatory bowel disease: the clot thickens. Am J Gastroenterol. 2007;102:174-186.

16. Papa A, Danese S, Grillo A, et al. Review article: inherited thrombophilia in inflammatory bowel disease. Am J Gastroenterol. 2003;98:1247-1251.

17. Jackson LM, O'Gorman PJ, O'Connell J, et al. Thrombosis in inflammatory bowel disease: clinical setting, procoagulant profile and FVL. Q J Med. 1997;90:183-188.

18. Haslam N, Standen GR, Probert CS. An investigation of the association of the FVL mutation and inflammatory bowel disease. Eur J Gastroenterol Hepatol. 1999;11:1289-1291.

19. Helio T, Wartiovaara U, Halme L, et al. Arg506Gln factor V mutation and Val34Leu factor XIII polymorphism in Finnish 
patients with inflammatory bowel disease. Scand J Gastroenterol. 1999;34:170-174.

20. Koutroubakis IE, Sfiridaki A, Mouzas IA, et al. Resistance to activated protein $\mathrm{C}$ and low levels of free protein $\mathrm{S}$ in Greek patients with inflammatory bowel disease. Am J Gastroenterol. 2000;95:190-194.

21. Liebman HA, Kashani N, Sutherland D, et al. The FVL mutation increases the risk of venous thrombosis in patients with inflammatory bowel disease. Gastroenterology. 1998;115: 830-834.

22. Nagy Z, Nagy A, Karadi O, et al. The high prevalence of the FVL mutation in central European inflammatory bowel disease patients. Am J Gastroenterol. 2000;95:3013-3014.

23. Over HH, Ulgen S, Tuglular $\mathrm{T}$, et al. Thrombophilia and inflammatory bowel disease: does factor $\mathrm{V}$ mutation have a role? Eur J Gastroenterol Hepatol. 1998;10:827-829.

24. Zauber NP, Sabbath-Solitare M, Rajoria G, et al. FVL mutation is not increased in patients with inflammatory bowel disease. J Clin Gastroenterol. 1998;27:215-216.

25. Turri D, Rosselli M, Simioni P, et al. FVL and prothrombin gene mutation in inflammatory bowel disease in a Mediterranean area. Dig Liv Dis. 2001;33:559-562.

26. Vecchi M, Sacchi E, Saibeni S, et al. Inflammatory bowel disease are not associated with major hereditary conditions predisposing to thrombosis. Dig Dis Sci. 2000;45: 1465-1469.

27. Papa A, De Stefano V, Gasbarrini A, et al. Prevalence of FVL and the G20210A prothrombin-gene mutation in inflammatory bowel disease. Blood Coagul Fibrinol. 2000;11:499-503.

28. Haslam N, Standen GR, Probert CS. An investigation of the association of the prothrombin G20210A gene mutation and inflammatory bowel disease: factor II and IBD. Inflamm Bowel Dis. 2001;7:133-135.

29. Mahamud N, Molloy A, McPartlin J, et al. Increased prevalence of methylenetetrahydrofolate reductase C677 T variant in patients with inflammatory bowel disease and its clinical implications. Gut. 1999;45:389-394.

30. Fernandez-Miranda C, Martinez Prieto M, Casis Herce B, et al. Hyperhomocysteinemia and methylenetetrahydrofolate reductase $677 \mathrm{C} \rightarrow \mathrm{T}$ and $1298 \mathrm{~A} \rightarrow \mathrm{C}$ mutations in patients with inflammatory bowel disease. Rev Esp Enferm Dig. 2005;97: 497-504.

31. Oldenburg B, Van Tuyl BA, van der Griend R, et al. Risk factors for thromboembolic complications in inflammatory bowel disease: the role of hyperhomocysteinaemia. Dig Dis Sci. 2005;50:235-240.

32. Koutroubakis IE, Sfiridaki A, Tsiolakidou G, et al. Genetic risk factors in patients with inflammatory bowel disease and vascular complications: case-control study. Inflamm Bowel Dis. 2007;13:410-415.

33. Yilmaz S, Bayan K, Tuzun Y, et al. A comprehensive analysis of 12 thrombophilic mutations and related parameters in patients with inflammatory bowel disease: data from Turkey. J Thromb Thrombolysis. 2006;22:205-212.

34. Fatini C, Sticchi E, Sofi F, et al. Multilocus analysis in candidate genes ACE, AGT, and AGTR1 and predisposition to peripheral arterial disease: role of ACE D/-240 T haplotype. J Vasc Surg. 2009;50:1399-1404.

35. Zintzaras E, Zdoukopoulos N. A field synopsis and metaanalysis of genetic association studies in peripheral arterial disease: the CUMAGAS-PAD database. Am $J$ Epidemiol. 2009; 170:1-11.

36. Papa A, Danese S, Urgesi R, et al. Early atherosclerosis in patients with inflammatory bowel disease. Eur Rev Med Pharmacol Sci. 2006;10:7-11.

37. Koutroubakis IE. Venous thromboembolism in hospitalized inflammatory bowel disease patients: the magnitude of the problem is staggering. Am $J$ Gastroenterol. 2008;103: $2272-2280$

38. Shen J, Ran ZH, Tong JL, et al. Meta-analysis: the utility and safety of heparin in the treatment of active ulcerative colitis. Aliment Pharmacol Ther. 2007;26:653-663.

39. Geerts WH, Pineo GF, Heit JA, et al. Prevention of venous thromboembolism. Chest. 2004;126:338S-400S.

40. Carter MJ, Lobo AJ, Travis SP. Guidelines for the management of inflammatory bowel disease in adults. Gut. 2004;53 (suppl 5):V1-V16.

41. Grainge MJ, West J, Card TR. Venous thromboembolism during active disease and remission in inflammatory bowel disease: a cohort study. Lancet. 2010;375:657-663. 